\title{
LINGUÍSTICA DE CORPUS NA MÚSICA: ANÁLISE DE TEXTOS SOBRE IMPROVISAÇÃO MUSICAL EM PORTUGUÊS E ITALIANO
}

Tatiane Marques Calloni Mestranda em Letras (Língua e Literatura Italiana) pela Universidade de São Paulo (USP) tatiane.calloni@gmail.com

\section{RESUMO}

Este trabalho pretende demonstrar como o campo musical pode representar uma rica fonte de pesquisas linguísticas e culturais. Também é nosso objetivo incentivar a tradução de material dedicado ao ensino e à teoria da música, visando expandir a quantidade de material especializado na área. Para tanto, realizamos uma pesquisa introdutória guiada pelo corpus, por meio da construção de dois corpora de especialidade em português e italiano sobre improvisação musical e analisamos os resultados com o auxílio do conjunto de programas WordSmith Tools. Obtivemos três resultados relevantes: 1) pouco material de fácil acesso, em português, na área de música; 2) relevante influência cultural de cada país na abordagem do tema; 3) interferência do inglês na língua italiana em áreas de conhecimento técnico. Esperamos que esses resultados preliminares possam incentivar futuras pesquisas linguísticas na área da música.

Palavras-chave: Linguística de Corpus, léxico, música.

\section{ABSTRACT}

The present paper aims to demonstrate how the field of music can be a rich source of linguistic and cultural research. It is also our objective to encourage the translation of material related to music education and music theory in order to expand the amount of specialized material in the area. We conducted a preliminary corpus driven research by means of the compilation of two specialized corpora related to musical improvisation in Portuguese and Italian language. Next, we analyzed the results with the aid of the program WordSmith Tools. Finally, we obtained three relevant results: 1) scarcity of easily accessible material in Portuguese in the field of music; 2) relevant cultural influence of each country's approach to the subject; 3) English interference on Italian language in areas of technical knowledge. We hope that these preliminary results will stimulate further linguistic research on music.

Keywords: Corpus linguistics, lexicon, music. 


\section{Introdução}

A pressuposição de que música e estudos linguísticos são dois mundos completamente diferentes é muito comum. Porém, se analisarmos atentamente, será possível constatar que existem muitas pontes ligando ambos, assim como ocorre em outras áreas do conhecimento. Finatto (2014) exemplifica a questão da interdisciplinaridade indicando que equipes de pesquisadores, terminólogos e linguistas contam com a ajuda de cientistas da informação, comunicação e computação. Esses profissionais contribuem com dados diferentes sobre um mesmo objeto de estudos, dentro de suas próprias áreas de domínio. Esse diálogo também pode ocorrer entre língua e música.

Inicialmente, pretendíamos pesquisar os termos técnicos mais frequentes em tratados italianos de música do século XVII e compreender como eles haviam sido traduzidos para o português. Nossa motivação surgiu diante da descoberta de várias traduções de tratados que ocorreram, e estão ocorrendo, na Escola de Comunicação e Artes da Universidade de São Paulo (ECA), como projetos de Mestrado e Doutorado. Essas traduções são feitas por alunos com formação em música que, na maioria dos casos, não possuem conhecimentos técnicos de tradução.

O principal obstáculo que impossibilitou a continuação de nossa pesquisa foi a falta de traduções em português dos principais tratados italianos que pretendíamos analisar. Decidimos, então, redirecionar o foco de nosso trabalho para a análise de textos teóricos, em português e italiano, relacionados à improvisação musical.

Através dessa pesquisa, esperamos constatar quais são os termos mais utilizados na área da improvisação e como eles podem ser analisados com o auxílio da Linguística de 
Corpus. Também pretendemos demonstrar como a música representa uma área do conhecimento que carece de material e pesquisas voltadas para o estudo linguístico, e que ganharia muito com futuras pesquisas. Certamente, resultados muito interessantes podem surgir, contribuindo para o esclarecimento da relação cultural que nós e outros países mantemos com a música, além de abrir espaço para questões linguísticas, como o estudo dos termos técnicos e termos em língua estrangeira que não são traduzidos para a língua de chegada. Esses resultados também poderiam fornecer uma base para a elaboração de material de apoio a alunos, pesquisadores e tradutores que precisam lidar com textos sobre música; lexicógrafos que pretendem elaborar dicionários e glossários; e professores, para que possam usufruir de uma quantidade maior de material em suas aulas.

\section{Linguística de Corpus hoje}

A Linguística de Corpus está avançando e tornando-se conhecida dentro e fora do meio acadêmico, graças às várias possibilidades que oferece aos pesquisadores e interessados em geral, além de representar mais um elemento que possibilita novas descobertas para professores, alunos e tradutores. Biber e Reppen (2015) descrevem a Linguística de Corpus como:

[...] uma abordagem de pesquisa que facilita investigações empíricas da variação e uso da língua, resultando em descobertas de pesquisa que têm generalidade e validade muito maior do que seria possível de outro modo. [...] a característica distintiva da linguística de corpus é a alegação de que efetivamente é possível "representar" um domínio do uso da língua com um corpus de textos e descrever empiricamente padrões 
linguísticos de uso através de análise desse corpus (BIBER; REPPEN, 2015, p. 1) ${ }^{\mathrm{i}}$

Compreendemos, então, que um corpus (plural: corpora) é um conjunto de textos especificamente coletados para a realização de pesquisas linguísticas. Há ainda diversos tipos de corpus, com conteúdo e propósito diferentes: falado, escrito, sincrônico, diacrônico, de amostragem, de aprendiz, de língua nativa, de estudo, entre outros (SARDINHA, 2004). Nesta pesquisa, trabalhamos com corpora de especialidade, contendo apenas textos restritos a uma determinada área do conhecimento, e de referência, formados por muitos textos de assuntos gerais. Uma das principais diferenças entre ambos, além da especificidade, é o tamanho. O corpus de referência procura abranger a maior quantidade possível de textos de uma língua, sobre qualquer conteúdo, e é fundamental para que possamos extrair as palavras-chave, ou termos técnicos, dos corpora de especialidade que construímos. Todo esse processo é feito através de softwares específicos e será descrito na metodologia.

Assim como na música, há vários debates sobre o que é, de fato, a Linguística de Corpus. Afinal, ela é uma disciplina ou uma metodologia? Segundo Cheng (2012), essa questão é importante, pois influencia a abordagem adotada pelo pesquisador em seus estudos. Há pesquisadores, como McEnery et al. (2006), que utilizam a Linguística de Corpus como uma ferramenta para testar teorias já existentes sobre a linguagem através da comparação de resultados obtidos pela análise de corpus e, portanto, defendem a classificação de metodologia. Já pesquisadores como Tognini-Bonelli (2001) e Biber (2009) consideram a Linguística de Corpus uma disciplina e trabalham com corpus para desenvolver novas teorias sobre a linguagem (CHENG, 2012). Portanto, não é possível indicar qual das correntes (teórica ou metodológica) está correta ou equivocada, já que 
ambas são utilizadas por pesquisadores da área e resultam em várias pesquisas interessantes.

\section{Considerações gerais sobre a música}

\subsection{A música na Itália e no Brasil}

Há uma grande discussão sobre a definição de música. Ela pode ser analisada como arte, linguagem, ciência, ou como uma combinação dessas três opções, principalmente em estudos musicoterápicos (utilização da música para tratamento emocional, psicológico e físico). O fato é que, independentemente da definição, a música está presente em nosso cotidiano e causa as mais diversas reações e sensações. Alguns se encantam por sua beleza, pelos sentimentos que provoca, e não sentem necessidade de conhecer sua estrutura para apreciá-la. Já outros acabam enveredando pelo caminho da teoria, dos números e dos termos específicos que a regem, buscando descobrir como a música é arquitetada e como podemos passar do papel de receptor ao papel de criador musical.

A história da música teve início em tempos muito remotos e recebeu grandes contribuições na Itália, conforme demonstramos através de alguns exemplos indicados a seguir, todos retirados do livro de Lovelock (1953). Em primeiro lugar, a igreja representou um papel importante no desenvolvimento da música, pois foi responsável por muitas composições sacras que eram utilizadas em seus rituais. Já a partir do século XIV, Florença começou a ganhar destaque na história da música e no século XVI, o 
madrigal, um tipo de composição vocal, desenvolveu-se expressivamente. A ópera também é outro legado importante da Itália na música. Agradou tanto ao público na época de seu surgimento que onze teatros de ópera foram construídos em Veneza. Por fim, conforme indicado por Lovelock (1953), citamos o violino, cuja origem é italiana. Os violinos Stradivarius, criados por Antonio Stradivari, ainda hoje são os mais famosos e cobiçados do mundo.

Com relação à música no Brasil, indicamos as afirmações de Kiefer (1977) em seu livro. Segundo o autor, ainda há vários detalhes desconhecidos sobre o nosso passado musical. É conhecida, porém, a forte influência da música europeia em terras brasileiras, relacionada ao período da colonização. Os jesuítas, apesar de não serem considerados fundamentais ao desenvolvimento da música brasileira, empenharam-se em catequizar os índios através da música, forçando a inserção dos instrumentos e da tradição musical europeia em sua cultura. Kiefer (1977) considera esse fato um dos motivos pelos quais a música indígena praticamente não exerceu nenhuma influência em nossa história musical. Em seguida, cita a cultura africana e o modo como os escravos influenciaram profundamente a nossa música através de seu ritmo e dança. Todos esses fatores, e ainda muitos outros, contribuíram para o surgimento da música brasileira como ela é conhecida hoje.

Atualmente, a Música Popular Brasileira (MPB), a Bossa Nova e o Samba são gêneros reconhecidos e apreciados ao redor do mundo. Napolitano (2002, p. 27) afirma que: "A esfera da música popular urbana no Brasil tem uma história longa, constituindo uma das mais vigorosas tradições da cultura brasileira. E isso não é pouca coisa num país acusado de não ter memória sobre si mesmo". Ainda assim, a música no Brasil representa uma área informal e pouco valorizada, como pudemos observar, enquanto estudantes. 
Geralmente, vemos escolas que abrem e fecham em um curto espaço de tempo, conservatórios restritos e, principalmente, poucos textos de fácil acesso, que em geral são escritos por autores estrangeiros. Percebemos também um número expressivo de professores sem formação adequada na cidade de São Paulo, que oferecem aulas particulares e elaboram a própria apostila com base em outras, também informais, além de aproveitarem materiais como revistas e artigos da internet. Isso tudo para nos referirmos ao estudo da teoria musical em si.

\subsection{Definindo a improvisação musical}

A improvisação musical tornou-se um assunto recorrente nos trabalhos e pesquisas de pós-graduandos e professores da área, como André Campos Machado, da Universidade Federal de Uberlândia, e Rogério Luiz Moraes Costa, da Universidade de São Paulo. Segundo a definição de Dourado (2008, p. 166) em seu dicionário de termos musicais, a improvisação: "[...] consiste na criação (1) de ritmo, acompanhamento e melodia, livremente, à medida que se desenvolve [...], (2) sobre bases fixas preestabelecidas entre os executantes, como no jazz, ou ainda (3) por tradição musical". A improvisação pode parecer um conceito simples, mas envolve muito conhecimento e prática. A partir deste ponto é importante citar, conforme Goldoni (2013), que composição e improvisação não representam o mesmo conceito. Compor é elaborar uma obra inteira antes de sua execução. Já improvisar é criar, ao mesmo tempo em que se executa, algo que exige técnica e anos de estudo. Zen (2014) menciona que a improvisação na música de hoje parece não existir mais. O autor cita como exemplo a grande maioria de sites de música, CDs e shows que apresentam apenas composições 
elaboradas previamente. É raro encontrarmos material dedicado a obras improvisadas, isto é, criadas espontaneamente, enquanto são gravadas ou executadas.

\subsection{O papel da Linguística de Corpus na música}

Ao pesquisarmos os trabalhos já desenvolvidos, e ainda em desenvolvimento, no Brasil, com o auxílio da Linguística de Corpus, encontramos muitos corpora dedicados a diversas áreas do conhecimento, desde os campos de estudo das línguas e literatura, aos estudos de léxico especializado em áreas como engenharia, biologia, medicina, e tantas outras. Citamos como exemplo o projeto COMET (Corpus Multilíngue para Ensino e Tradução), desenvolvido por pesquisadores do Departamento de Letras Modernas da Faculdade de Filosofia, Letras e Ciências Humanas da Universidade de São Paulo. O projeto oferece mais de vinte corpora para auxiliar as pesquisas linguísticas sobre os mais variados temas. No entanto, no decorrer de nossa pesquisa, não encontramos nenhum corpus dedicado ao campo da música. Pretendemos, então, levantar duas hipóteses que talvez expliquem essa lacuna.

A primeira hipótese refere-se à crença geral de que música é apenas uma manifestação estética e não faz parte do mundo acadêmico. Med (1996) desmistifica esse fato e afirma que a música além de uma arte, também é ciência, pois talento não é suficiente para a formação de um músico, sejam eles compositores ou intérpretes. É preciso aprender técnicas específicas que exigem anos de estudo e dedicação. A vasta literatura e estudos dedicados ao tema ao redor do mundo são, por si só, indicativos do quanto a música é constituída de saber científico.

A segunda hipótese é representada pela aparente escassez de textos confiáveis, 
em português, que sirvam de apoio ao estudo e à pesquisa, já que nem todos sabem ler textos em italiano, alemão, francês e até mesmo inglês, que representam línguas mais correntes nos textos da área. Ao procurarmos esse tipo material, os resultados mais comuns são apostilas, muitas vezes elaboradas por entusiastas e professores de música, voltadas às disciplinas que ministram; artigos, formais e informais, espalhados pela internet; e poucos livros teóricos, geralmente de autores estrangeiros. Adolfo (2002) é um dos autores que mencionam a questão da falta de material na introdução de seu livro.

Faz-se necessário criar didática musical quando há carência do que consideramos material ideal para o aprendizado. Desde 1989, quando lancei o Livro do músico, venho tentando suprir a falta de material na área da música no Brasil com livros para piano, teclado, harmonia, composição e arranjo. Todos os livros nasceram da experiência didática em aula e de apostilas que criei para meus alunos (ADOLFO, 2002, p. 16).

Com relação ao Brasil, encontramos alguns trabalhos dedicados ao estudo de letras de música através da Linguística de Corpus, como exemplificado por Bértoli-Dutra (2014) que analisou letras de música em inglês. Outros, como Delfino (2016) e Delfino e Pitombeira (2017), também analisaram letras de música, com foco no ensino de línguas estrangeiras. Já no exterior, há ocorrência de pesquisas como as desenvolvidas por Serra (2014) e Gulati et al. (2014), voltadas à construção de corpora para pesquisas relacionadas ao estudo da música.

\section{Metodologia}

Para a construção dos corpora, seguimos os passos detalhadamente explicados por Almeida e Aluísio (2006). Em primeiro lugar, selecionamos artigos publicados em 
revistas científicas e teses de Doutorado, ainda que o recorte temático não estivesse definido. Nenhum dos recortes feitos apresentava uma quantidade de material razoável para o trabalho, até iniciarmos uma busca por artigos e teses sobre improvisação musical, que mesmo sendo um tema aparentemente mais recorrente, também ofereceu um número limitado de textos e consumiu dias de pesquisa.

Finalizada a busca pelos textos, delimitamos nossos corpora de especialidade, em português e italiano, a nove artigos e uma tese de Doutorado, publicados entre os anos de 2010 e 2016 . Esse número foi definido com base na quantidade de material disponível, encontrado por meio da internet, totalizando dez textos para cada corpus. Um número baixo, mas eficaz, ao evidenciar informações interessantes durante a etapa de análise. Gostaríamos de ter adicionado mais teses, o que não foi possível, pois muitas pesquisas italianas não podem ser consultadas gratuitamente. Como o balanceamento dos corpora foi feito, principalmente, pela quantidade de textos, não adicionamos um número maior de teses em português. Balancear os corpora significa equilibrá-los a partir de alguma característica comum, como quantidade de textos ou palavras, tipo textual, gênero discursivo e outros. Contabilizando por páginas, o corpus do português apresentou um total de 443 e o corpus do italiano, 494. Em seguida, convertemos todos os textos, de formato .pdf para .txt, e limpamos caracteres indesejados e acentuação errada. 0 tamanho final do corpus não foi motivo de preocupação porque os textos representavam satisfatoriamente a variação linguística que pretendíamos analisar, esse sim um fator importante.

Por fim, selecionamos nossos corpora de referência. Como corpus de referência do português utilizamos o Lácio-Ref, desenvolvido através do projeto Lácio-Web, iniciado em 2002 e fruto de trabalho conjunto entre o Núcleo Interinstitucional de Linguística 
Computacional (NILC), Instituto de Matemática e Estatística (IME), e a Faculdade de Filosofia, Letras e Ciências Humanas (FFLCH), todos da Universidade de São Paulo. Já como corpus de referência do italiano utilizamos o corpus PAISÀ, constituído de textos coletados da internet, elaborado através do projeto PAISÀ (Piattaforma per I'Apprendimento dell'Italiano Su corpora Annotati), que surgiu da parceria entre Università di Bologna, Università di Trento, Accademia Europea di Bolzano e Consiglio Nazionale delle Ricerche di Pisa. Esse projeto se desenvolveu entre os anos de 2009 e 2012.

\subsection{Análise com o Wordsmith Tools}

O Wordsmith Tools é um conjunto de programas de análise e listagem de palavras, disponível tanto em versão de teste quanto em versão paga. Há também o AntConc, que realiza as mesmas funções e é disponibilizado gratuitamente. Priorizamos o WordSmith Tools, versão 7, porque foi através dele que conseguimos processar o corpus de referência do italiano. O AntConc, versão 3.4.4w, apresentou erros que impossibilitaram o processamento do arquivo. Acreditamos que isso ocorreu porque o tamanho do corpus em italiano, de aproximadamente 1,40 gigabytes, era muito grande para ser processado por este programa.

Dentro do programa escolhido há três ferramentas principais que foram utilizadas na nossa pesquisa: WordList, que elabora uma lista com todas as palavras presentes no corpus e indica a frequência com que aparecem, além de outras informações; KeyWord, que através da comparação entre a lista de palavras do corpus de especialidade e a lista do corpus de referência, oferece uma terceira lista contendo apenas as palavras-chave do 
texto de especialidade, ou seja, palavras que são proporcionalmente mais frequentes ou relevantes no corpus de especialidade que no corpus de referência, apresentando assim possíveis candidatos a termo; e Concord, que aponta ao pesquisador, após a indicação de determinada palavra, o contexto em que ela está inserida e as palavras que geralmente a acompanham, conhecidas como colocados. Elaboramos, então, a lista de palavras e a lista de palavras-chave, que nos indicou as ocorrências mais específicas dos textos sobre improvisação musical.

Figura 1 - Exemplo de lista de palavras-chave gerada através do WordSmith Tools para o corpus em português

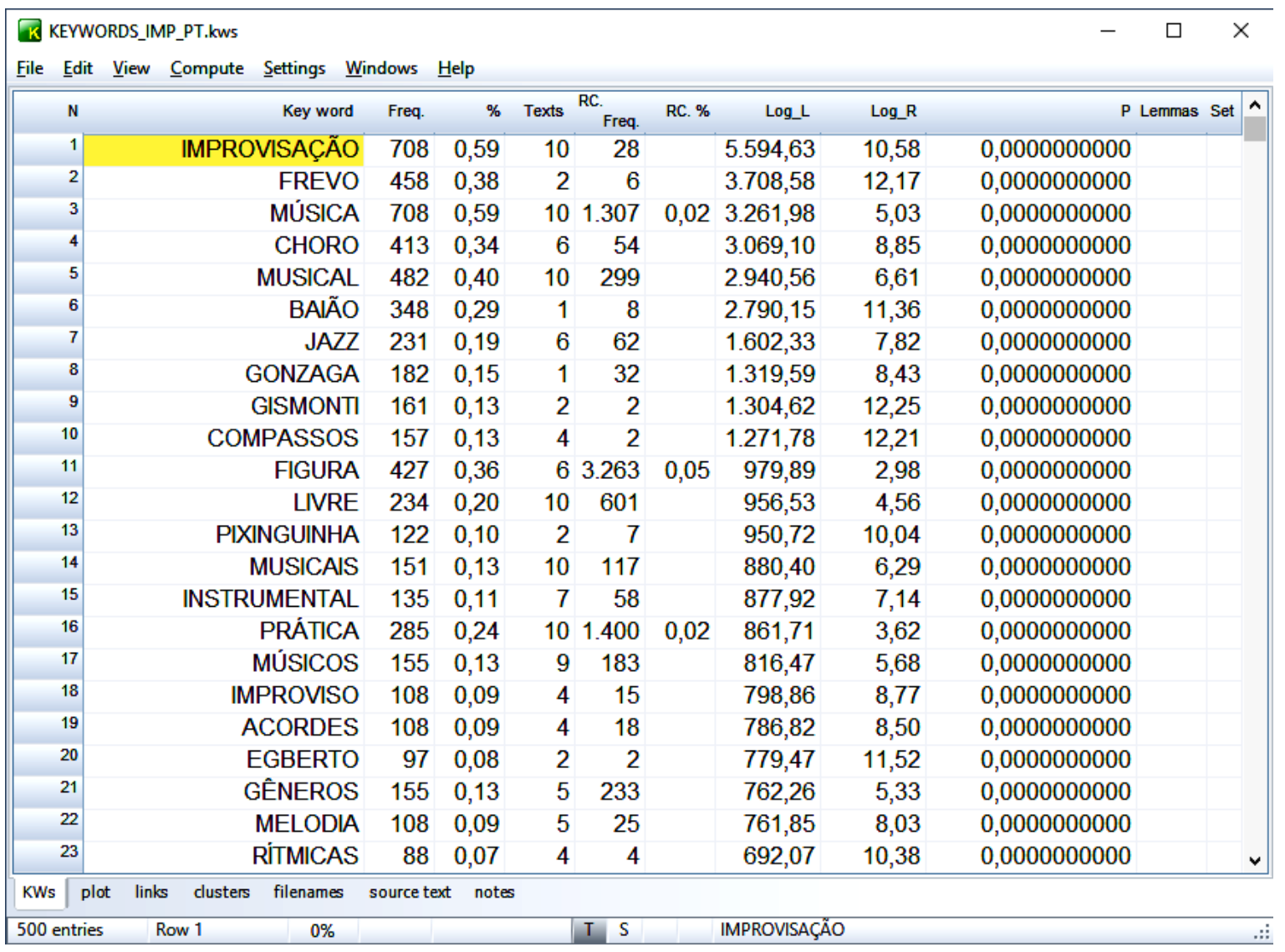

A seguir, apresentaremos os dados encontrados após a análise dos corpora por meio de software e refletiremos sobre alguns dos principais aspectos observados. 


\section{Resultados e discussões}

Ao falar sobre improvisação musical, cada país aborda um aspecto diferente do tema. Os artigos e a tese em português indicaram gêneros de música popular e instrumental brasileira em que os intérpretes costumam improvisar com frequência. Apareceram na lista de palavras-chave os gêneros choro, baião e frevo. Também são citados grandes compositores e intérpretes nacionais. Já no italiano, o único gênero nacional registrado na lista foi a ópera. Notamos também que um número considerável de termos que apareceram na lista de palavras-chave eram relacionados à teoria musical e faziam referência à estrutura musical propriamente dita.

Figura 2 - Palavras-chave mais relevantes nos corpora de especialidade

\begin{tabular}{|c|c|c|c|c|c|c|c|}
\hline \multicolumn{8}{|c|}{ PALAVRAS-CHAVE MAIS RELEVANTES } \\
\hline \multicolumn{4}{|c|}{ PORTUGUÊS } & \multicolumn{4}{|c|}{ ITALIANO } \\
\hline $\mathbf{1}$ & IMPROVISAÇÃO & 2 & FREVO & $\mathbf{1}$ & IMPROVVISAZIONE & 2 & PERFORMANCE \\
\hline 3 & MÚSICA & 4 & CHORO & 3 & JAZZ & 4 & MUSICA \\
\hline 5 & MUSICAL & 6 & BALÃO & 5 & MUSICALE & 6 & IMPROVISATION \\
\hline 7 & JAZZ & $\mathbf{8}$ & GONZAGA & 7 & OPERA & $\mathbf{8}$ & ALPERSON \\
\hline 9 & GISMONTI & 10 & COMPASSOS & 9 & DAVIES & 10 & KIVY \\
\hline 11 & LIVRE & 12 & PIXINGUINHA & 11 & COMPOSIZIONE & 12 & KANLA \\
\hline 13 & INSTRUMENTAL & 14 & PRÁTICA & 13 & CONTRAFFATTURA & 14 & INVARIANZA \\
\hline 15 & MÚSICOS & 16 & IMPROVISO & 15 & ONTOLOGLA & 16 & LEVINSON \\
\hline 17 & ACORDES & 18 & GÊNEROS & 17 & PARTITURA & 18 & DODD \\
\hline 19 & MELODIA & 20 & RÍTMICAS & 19 & PROPRIETÀ & 20 & BERTINETTO \\
\hline 21 & ELEMENTOS & 22 & ACORDE & 21 & FREE & 22 & WOLTERSTORFF \\
\hline 23 & NOTAS & 24 & IDEIA & 23 & PLATONISMO & 24 & IMPROVVISATORE \\
\hline 25 & RÍTMICA & 26 & PERFORMANCE & 25 & PERFORMER & 26 & SUONO \\
\hline 27 & BANDOLIM & 28 & REPERTÓRIO & 27 & IMPROVVISARE & 28 & CONCETTO \\
\hline 29 & HERMETO & 30 & POPULAR & 29 & COMPOSITORE & 30 & SPARTI \\
\hline 31 & COMPASSO & 32 & JACOB & 31 & IMPROVVISATA & 32 & REGISTRAZIONE \\
\hline 33 & MELÓDICA & 34 & DIRUTA & 33 & GOODMAN & 34 & GOEHR \\
\hline 35 & GRAVAÇÕES & & & 35 & PRATICA & & \\
\hline
\end{tabular}

O material em italiano evidenciou uma pesquisa bem mais teórica sobre a 
improvisação musical ao indicar em sua lista de palavras-chave o nome de vários teóricos, além de um estudo (Ontologia Musical) e uma corrente filosófica (Platonismo), enquanto na lista do português apenas um teórico, Girolamo Diruta, é citado. Coincidentemente, Diruta foi um organista, compositor e teórico musical italiano. Também é interessante notar que enquanto a lista do português não apresenta nenhum termo em inglês, a lista do italiano apresenta três: improvisation, free e performer. Ao analisarmos a palavra free com o concordanciador, descobrimos que ela representa o colocado de três expressões muito utilizadas nos textos do corpus: free music, free jazz e free improvisation.

As palavras livre e free chamaram nossa atenção. Livre apareceu na lista de palavras-chave do português em 11일 lugar, enquanto free apareceu na lista do italiano em 21‥ Ao gerarmos as concordâncias dessas palavras com a ferramenta Concord, descobrimos que elas eram acompanhadas de colocados bem específicos: improvisação livre, livre improvisação, free music, free improvisation e free jazz. Em português, livre refere-se quase exclusivamente à improvisação, enquanto no italiano também qualifica music e jazz. Aqui constatamos outra característica da língua italiana que se confirma ao observarmos esses dados: a influência do inglês sobre o italiano, não apenas na língua cotidiana, mas também em áreas técnicas do conhecimento. Por que os italianos preferem free improvisation em vez de improvvisazione libera? Essa pergunta poderia alimentar novas pesquisas. Já a lista do português indica que, no Brasil, a presença de palavras estrangeiras, pelo menos no âmbito da improvisação musical, é praticamente nula, com exceção da palavra jazz, que indica um gênero musical norte americano e é mundialmente utilizada. 
Figura 3-Concordâncias da palavra livre geradas pelo Concord

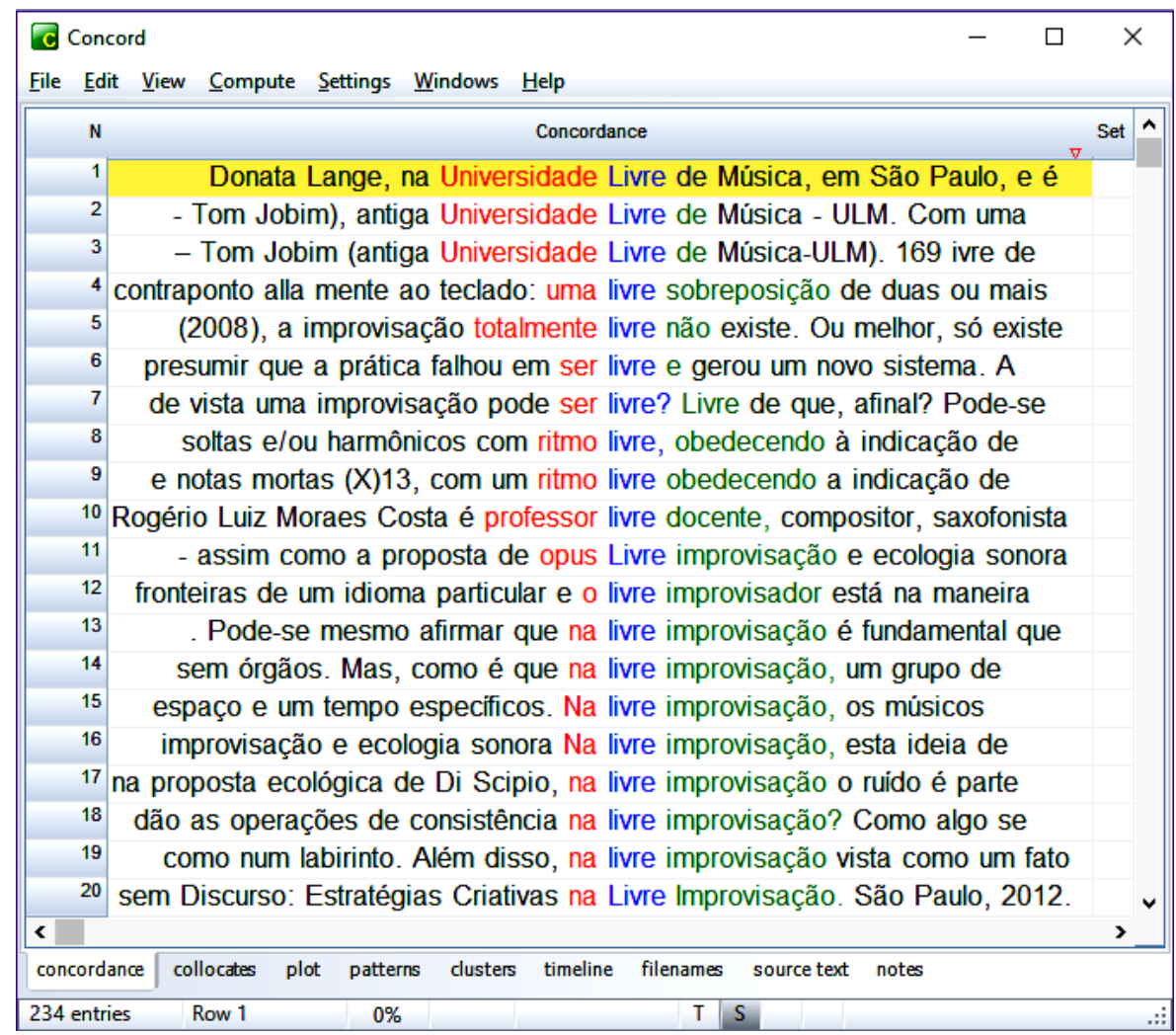

Figura 4 - Concordâncias da palavra free geradas pelo Concord

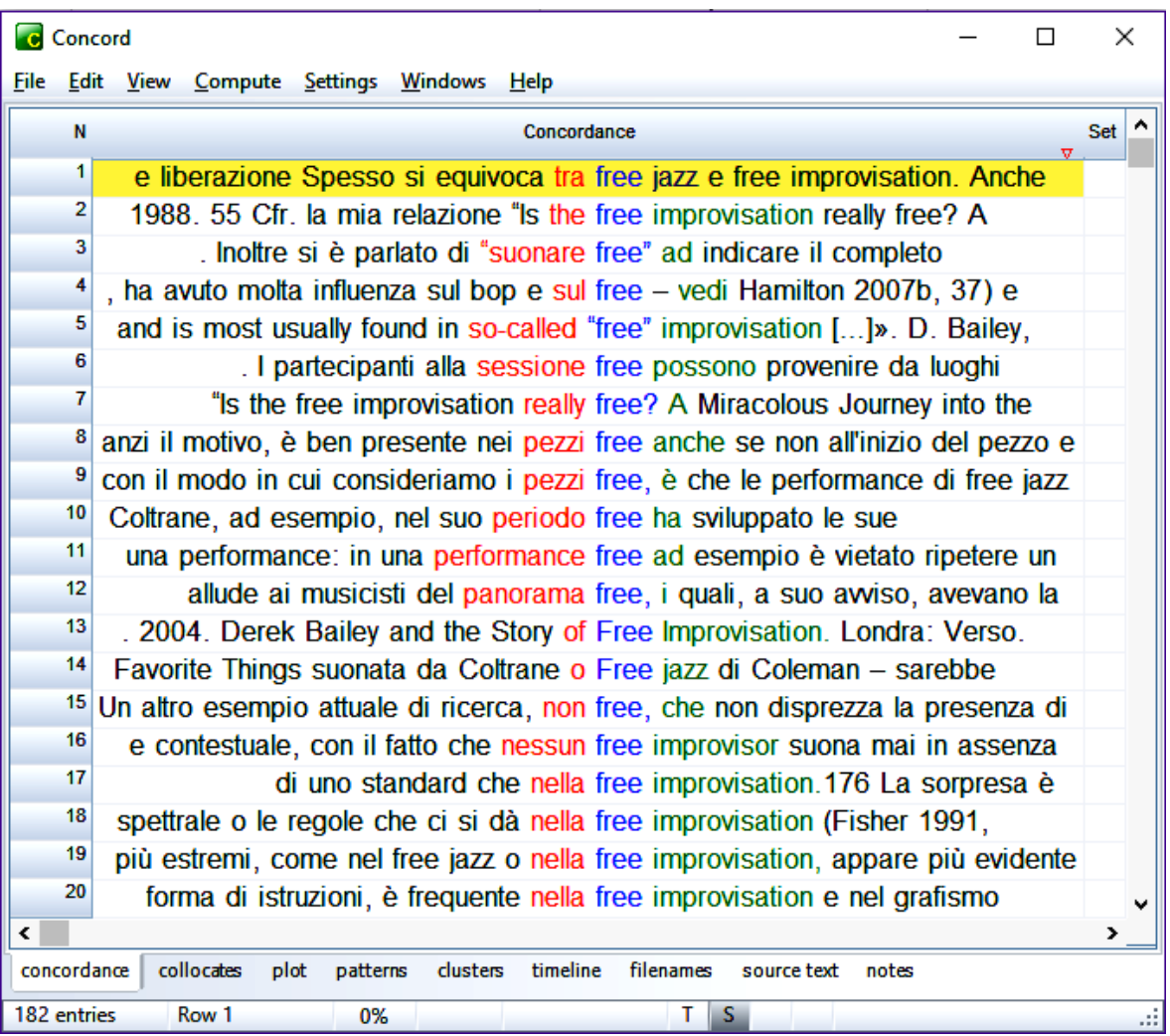


Apresentadas as diferenças, falaremos agora das semelhanças. A palavra improvisação é a primeira da lista, tanto em português quanto em italiano (improvvisazione). Outras palavras que estão presentes nas duas listas são: música/musica, performance/performance, prática/pratica e musical/musicale. Aproveitamos para mencionar uma reflexão de Tognini-Bonelli (2002) acerca de um comentário de Firth (1968) sobre termos técnicos. A autora diz que apesar de não ser possível decifrar o significado de um termo técnico a partir de seu significado em língua geral, o mesmo termo estará sempre sujeito a mudanças de significado, produzidas pelo contexto no qual está sendo utilizado. Ou seja, se olharmos para essas palavras-chave, podemos não entender o que elas significam ao buscarmos seus significados mais gerais em língua corrente, porém se inserirmos essas mesmas palavras-chave em um contexto de uso diferente, que não o musical, certamente elas irão adquirir um novo significado.

Seguindo adiante, ambas as listas evidenciam, como dissemos, a palavra jazz. Esse é um resultado esperado quando falamos de improvisação na música, afinal o jazz é um dos gêneros mais famosos por sua ampla utilização da improvisação, o que faz dele um tema frequente de estudos e pesquisas em várias línguas. Goldoni (2013) cita o jazz ao continuar sua explicação sobre composição e improvisação e indica que nesse gênero ocorre integração entre os dois atos.

\section{Considerações finais}

Napolitano (2002, p. 8) dialoga com a intenção de nossa pesquisa ao afirmar que: "a música não é apenas boa para ouvir, mas também é boa para pensar". A música é boa para pensar, inclusive, em outras áreas de pesquisa, conforme procuramos demonstrar 
com este trabalho introdutório, através da constatação de três resultados principais. 0 primeiro resultado é prático e indica a escassez de material relacionado à música em português e o difícil acesso ao material em italiano, o que demonstra a necessidade de novas traduções, material teórico e didático produzido no Brasil e pesquisas que forneçam dados auxiliares a esses projetos.

O segundo resultado encontra-se na base cultural e indicou como a visão de mundo de cada país acaba influenciando o modo como analisam a música. Os textos italianos apresentaram um número de teóricos citados muito superior aos textos em português. Em compensação, os textos produzidos no Brasil mencionaram muito mais gêneros populares brasileiros, além de compositores e intérpretes nacionais, o que talvez confirme a forte veia criativa que nutre o país.

Por fim, como terceiro resultado, voltado à análise lexical, ocorreu a confirmação da presença do inglês na língua italiana, principalmente em termos técnicos. Os termos que obtivemos através da lista de palavras-chave indicam o modo como os italianos costumam se referir a essa especialidade da música. Isso nos leva a crer que uma pesquisa mais profunda, com uma quantidade maior de textos, poderia evidenciar um número expressivo de palavras-chave que ajudariam na tradução de textos especializados.

A dificuldade em encontrar textos que pudessem ser trabalhados neste projeto tornou-se já um indício do quanto podemos colaborar. Com esses resultados preliminares, esperamos demonstrar que, ao realizarmos uma pesquisa guiada por corpus em uma quantidade limitada de textos sobre improvisação musical, conseguimos obter informações muito interessantes sobre as diferentes visões culturais do Brasil e da Itália sobre a música e o modo como cada um conduz suas pesquisas sobre o tema, além de 
constatarmos a terminologia utilizada, a ocorrência de estrangeirismos e a observação de colocados.

Concluímos, esperando que esses resultados, mesmo que sucintos, tenham cumprido a missão de demonstrar como o campo musical oferece variadas oportunidades de pesquisa, com resultados que podem beneficiar outros trabalhos e públicos diversos.

\section{Referências}

ADOLFO, A. Música: leitura, conceitos, exercícios. Rio de Janeiro: Lumiar Editora, 2002.

ALMEIDA; G. M. B.; ALUÍSIO; S. M. O que é e como se constrói um corpus? Lições aprendidas na compilação de vários corpora para pesquisa linguística. Calidoscópio, vol. 4, n. 3, set/dez 2006, p. 156-178.

ANTCONC. Version 3.5.7. Tokyo, Japan: Waseda University: Anthony, L., 2018. Disponível em: <http://www.laurenceanthony.net/software>. Acesso em: 28 ago. 2018.

BERBER SARDINHA, T. Linguística de corpus. São Paulo: Manole, 2004.

BÉRTOLI-DUTRA, P. Convergência lexical entre letras de música e inglês geral: um estudo baseado em corpus. Letras \& Letras, v. 30, n. 2, jul/dez 2014, p. 401-420.

BIBER, D. A corpus-driven approach to formulaic language in English: multi-word patterns in speech and writing. International Journal of Corpus Linguistics, v. 14, n. 3, 2009, p. 275311.

BIBER, D.; REPPEN, R. (eds.). The Cambridge Handbook of English Corpus Linguistics. Cambridge: Cambridge University Press, 2015.

CHENG, W. Exploring corpus linguistics: language in action. New York: Routledge, 2012.

DELFINO, M. C. N. Uso de música para o ensino de inglês como língua estrangeira em um ambiente baseado em corpus. Dissertação (Mestrado em Linguística Aplicada e Estudos da Linguagem) - Programa de Pós-graduação em Linguística Aplicada e Estudos da Linguagem. Pontifícia Universidade Católica de São Paulo, 2016. 
DELFINO, M. C. N.; PITOMBEIRA, C. V. Diálogos: linguística de corpus e complexidade no ensino de le com letras de música. Revista CBtecLE, v. 01, 2017, p. 214-228.

DOURADO, H. A. Dicionário de termos e expressões da música. 2. ed. São Paulo: Editora 34, 2008.

FINATTO, M. J. B. New methods for specialized lexicography: Brazilian approach examples. Lexicographica, vol. 30, n. 1, 2014, p. 247-261.

GOLDONI, D. Composizione e improvvisazione: dove sta la differenza? Aisthesis, anno VI, special issue, 2013, p. 133-153.

GULATI, S.; ISHWAR, V.; KODURI, G. K.; SERRA, X.; SRINIVASAMURTHY, A. Corpora for Music Information Research in Indian Art Music. Proceedings of Joint International Computer Music Conference/Sound and Music Computing Conference. Athens, Greece, Sep 2014.

KIEFER, B. História da música brasileira: dos primórdios ao início do século XX. Porto Alegre: Movimento, 1977.

LACIO-WEB. Universidade de São Paulo, 2004. Disponível em:

<http://143.107.183.175:22180/lacioweb/index.htm>. Acesso em: 28 ago. 2018.

LOVELOCK, W. História concisa da música. Tradução Álvaro Cabral. São Paulo: Martins Fontes, 1953.

MCENERY, T.; XIAO, R.; TONO, Y. Corpus-based language studies: an advanced resource book. London: Routledge, 2006.

MED, B. Teoria da música. 4. ed. Brasília, DF: Musimed, 1996.

NAPOLITANO, M. História e música: história cultural da música popular. Belo Horizonte: Autêntica, 2002.

PROGETTO PAISÀ. Università Di Bologna, CNR Pisa, Accademia Europea Di Bolzano, Università Di Trento, 2012. Disponível em: <http://www.corpusitaliano.it/>. Acesso em: 28 ago. 2018.

PROJETO COMET. Universidade de São Paulo, 2018. Disponível em:

<http://comet.fflch.usp.br/>. Acesso em: 28 ago. 2018.

SERRA, X. Creating Research Corpora for the Computational Study of Music: the case of the CompMusic Project. AES 53rd International Conference, London, UK, January 2014, p. 27-29. 
TOGNINI-BONELLI, E. Corpus linguistics at work. Amsterdam/Philadelphia, PA: John Benjamins, 2001.

TOGNINI-BONELLI, E. Between Phraseology and Terminology in the Language of Economics. NUCCORINI, S. (ed.). Phrases and Phraseology: data and descriptions. Bern: Peter Lang, 2002.

WORDSMITH Tools. Version 7.0. Lexical analysis software. Oxford University Press, 2016. Disponível em: <http://lexically.net/wordsmith/>. Acesso em: 28 ago. 2018.

ZEN, G. Che cos'è l'improvvisazione musicale? 2014. Tese (Doutorado em Filosofia) Scuola Dottorale di Ateneo, Università Ca' Foscari Venezia, Veneza, 2014.

Recebido em 28 de agosto de 2018.

Aceite em 30 de setembro de 2018.

\footnotetext{
i "[...] a research approach that facilitates empirical investigations of language variation and use, resulting in research findings that have much greater generalizability and validity than would otherwise be feasible. [...] the distinctive characteristic of corpus linguistics is the claim that it is possible to actually "represent" a domain of language use with a corpus of texts, and possible to empirically describe linguistic patterns of use through analysis of that corpus". (Tradução nossa).
} 